University of the Pacific

Scholarly Commons

College of the Pacific Faculty Articles

All Faculty Scholarship

3-12-2007

\title{
To Boldly Go: Current Work and Future Directions in Mathematics and Popular Culture
}

\author{
Christopher D. Goff \\ University of the Pacific, cgoff@pacific.edu \\ Sarah Greenwald \\ Appalachian State University
}

Follow this and additional works at: https://scholarlycommons.pacific.edu/cop-facarticles

Part of the Mathematics Commons

\section{Recommended Citation}

Goff, C. D., \& Greenwald, S. (2007). To Boldly Go: Current Work and Future Directions in Mathematics and Popular Culture. PRIMUS: Problems, Resources, and Issues in Mathematics Undergraduate Studies, 17(1), 1-7. DOI: 10.1080/10511970601126852 https://scholarlycommons.pacific.edu/cop-facarticles/265 


\section{To Boldly Go: \\ Current Work and Future Directions \\ in Mathematics and Popular Culture}

\section{Christopher D. Goff and Sarah J. Greenwald University of the Pacific and Appalachian State University}

\section{Introduction to This Issue}

Mathematics begins with definitions. Therefore, we will begin by attempting to define what is meant by "popular" culture. Historically, popular culture was defined by its opposition to "high" culture: such as the opera, historic art, classical music, traditional theater or literature [1]. High culture was for the upper class; popular culture, the lower. But the distinction between the two has always been blurry and became even more so with the advent of radio, television, film, and the mass production of culture in the middle of the twentieth century.

Today, one can find many competing definitions of popular culture from various sources, both academic and popular. According to John Storey [8], "Culture' in cultural studies [which encompasses the study of popular culture] is defined politically rather than aesthetically as the texts and practices of everyday life." The question of what counts as popular culture is thus open to debate, a debate that is itself an inherent part of any arena of cultural studies. In other words, as noted by the popularly created Wikipedia [14], "Curiously, though almost everybody spends their lives immersed in popular culture, nobody seems able to agree on what popular culture consists of."

Because of this ongoing conversation, any definition we give here would necessarily be more or less subjective. As mathematicians, we are in a slight quandary: definitions are the foundation of mathematics, largely due to their objectivity. How then can we study popular culture if we cannot agree on what it is? To avoid this dilemma, we will eschew defining popular culture specifically, but will include movies, television shows (both scripted and unscripted), plays, musicals, "popular" books, and even advertising. This issue will examine mathematical content, broadly defined, in a variety of popular media.

This collection marks the second time that PRIMUS has devoted an issue specifically to mathematics and popular culture [6]. Many of the papers in this collection were first presented in a contributed paper session, entitled "Mathematics and Popular Culture" at the Joint Meetings in San Antonio, January 2006. The authors of this introduction publicized the following call for abstracts:

One way that mathematics and popular culture interact is through Hollywood. Computer animators for blockbuster filmmakers like Pixar use mathematical algorithms in their work. In addition, television series such as $N U M B 3 R S$, and 
movies like A Beautiful Mind, Mean Girls, and Proof (expected in 2005) offer varied portrayals of people with mathematical talent. These references to mathematics in popular culture can reveal, reflect, and even shape how society views mathematics. In the classroom, using popular culture can be a powerful technique for engaging diverse audiences. Capitalizing on student enjoyment of popular culture can alleviate math anxiety, energize shy and quiet students, and provide a creative introduction to an in-depth study of the related mathematics. This session invites presentations on all aspects related to mathematics and popular culture, including music, movies, television, artwork, and other media. Presentations could focus on how mathematics is changing Hollywood and movies, or how popular culture can be used to understand the way society views mathematicians and their mathematics. Conversely, presentations could focus on how appearances of and references to mathematics in popular culture have been used creatively and effectively in mathematics courses to reduce math anxiety and motivate students to explore significant mathematics.

The session generated much interest, was referenced in the local newspaper [2], and was extremely well attended. Participants were invited to submit to this special issue of PRIMUS, and many did. In fact, the eight papers here evolved out of eighteen talks given at that MAA contributed paper session.

In the first article of this issue, Timothy P. Chartier describes one way in which mathematics helps to create popular culture, namely, through animation effects in Star Wars films. He also discusses how to incorporate such mathematical simulations in the classroom.

The next few papers explore how instances of mathematics referenced in the popular culture can be used to introduce relevant mathematical content in the classroom. Paul Coe, Peter Alonzi, Daniel Condon, and William Butterworth discuss the television game show Friend or Foe as a way to introduce game theory. In the next article, Cinnamon Hillyard describes her use of a variety of popular sources (movies, cartoons, advertising, television, and even a children's story) in a seminar-style course on Quantitative Reasoning. Mike Pinter discusses his experiences using books, movies, and a play in a first-year seminar course on the theme of "limitations."

Two papers explore ways to engage students with the representations not only of mathematics, but also of mathematicians in popular culture. Sarah J. Greenwald outlines a variety of ways that clips from the animated television sitcom Futurama and quotations from its highly mathematically educated writers have been used in the classroom. Cynthia E. Chin describes a recent successful production of the musical Fermat's Last Tango, which was adapted, directed, and performed by high school students.

The last two articles address broader issues that relate mathematics and popular culture to societal concerns. In other words, popular culture can shape the perceptions not only of students, but also of policymakers and other stakeholders in education. For example, Lynn Gieger discusses some of the myths evident in the portrayal of Jaime Escalante in the film Stand and Deliver as well as how these myths are reflected in "No Child Left Behind" legislation. The authors of the collection's final paper, Sarah J. Greenwald and Jill E. Thomley, discuss the impacts of representations of mathematically talented women in Hollywood and provide a framework for examining the messages such representations may 
convey.

\section{Copyright Issues}

It would be remiss to discuss popular culture in the classroom without highlighting related copyright issues. Copyright law has become much more complex in recent years and there is much confusion among educators regarding the Digital Millennium Copyright Act (DMCA) [11], the TEACH Act [13], and Fair Use Provisions [12]. One thing is for certain, as Larry Lessig has noted [4], "fair use in America simply means the right to hire a lawyer." In the past, educators were granted considerable leeway to use copyrighted material in the classroom. More recently, the climate has become much more restrictive, and there are many instances of court cases which might be surprising to educators [3, 7], such as court cases related to the use of portions of a book for educational purposes.

A university press objected to a major Southern university including a chapter of a book that, ironically, was about restrictive copyright regimes, in an electronic course reserve system that limited access to students in the class. In the second case, a publisher objected to the distribution of a chapter from a book prior to a lecture even though the author had retained copyright in the book and agreed to the distribution. [4]

If we had infinite amounts of money, we would just purchase copies of the desired works for the entire class. Since this is impractical, teachers must consider the legal implications of using small portions of copyrighted works in a fair use manner. As noted by the U.S. Copyright Office [12],

The distinction between fair use and infringement may be unclear and not easily defined. There is no specific number of words, lines, or notes that may safely be taken without permission. Acknowledging the source of the copyrighted material does not substitute for obtaining permission... The safest course is always to get permission from the copyright owner before using copyrighted material.

Of course it is not always possible to obtain permission, but educators do still have leeway for educational use. For example, it is generally accepted that even without permission from the copyright holder, educators can show a small portion played directly from a personallyowned commercial DVD in a face-to-face setting for educational purposes (e.g., see [5]). However, educators no longer enjoy the blanket protection of the past, which some called educational fair use. Copyright law is restrictive for educators, especially with regard to DVD protections and encoding (don't even think about it [11]), distribution (a big no - no [5]), and distance learning (a complicated set of guidelines [13]). While copyright laws make popular culture use more challenging, the benefits are well worth the effort to use it legally.

\section{Current Themes and Future Directions}

The articles in this issue showcase the power of popular culture, but they also highlight related cautionary themes. Here we discuss some of these themes and provide questions for 
future scholarly endeavors.

\section{Nerd, Genius, and Mad Scientist Stereotypes}

Representations of nerds, geniuses, and mad scientists proliferate in popular culture. Mathematician characters in the musical Fermat's Last Tango, in television shows such as $E U R^{e} K A$, Futurama and NUMB3RS, in numerous popular books, and in blockbuster movies like Good Will Hunting and Proof reinforce this stereotype. The mathematical powers of geniuses are sometimes equated with mental illness, such as John Nash in the movie A Beautiful Mind, or Christopher in the book The Curious Incident of the Dog in the Night-Time. Perhaps future work will examine the effect that these stereotypes have on students. Are they interested in the mathematics because of the character's quirkiness, or will they become discouraged because math does not come to them as easily as it does to the geniuses they see on the screen?

\section{The "Young Man's Game" Stereotype}

This theme is mentioned in one of the songs in Fermat's Last Tango, and it can also be found in Good Will Hunting, A Beautiful Mind, and Proof. In this case, mathematicians may be responsible for its prevalence. Hardy's A Mathematician's Apology mentions his deteriorating mathematical talents, and the Fields Medal, arguably the most prestigious international mathematics award, has (unofficially) incorporated this theme into its selection process. What does this mean to older male mathematicians? ... to younger male mathematicians? ... to female mathematicians of any age?

\section{Representations of Women and Minority Mathematicians}

As mentioned in the related article in this issue, media studies suggest that in the absence of real-life role models, children and adolescents form their own images of mathematicians from representations they see in the popular media. There has been a recent increase in the number of portrayals of mathematically talented women in popular culture, such as in the movies Ice Princess, Mean Girls, and Proof, and the television shows Angel, Futurama, and $N U M B 3 R S$, and The Simpsons devoted an entire episode to the mathematical talent of the character Lisa [10]. Yet there are very few representations of other underrepresented groups, aside from Jaime Escalante, a hispanic educator who is represented in the film Stand and Deliver, and a Globetrotter's physics team made up of Black players who help with mathematics in Futurama. How do our students respond to these representations (or lack of them)? What is our responsibility as educators when we discuss these representations in the classroom?

\section{Representations of Sexuality}

While not explicitly addressed in this issue, the sexual identity of mathematicians is a topic that arises in (or is explicitly left out of) movies, television shows, books, and other popular sources. Alan Turing's homosexuality has been the topic of documentaries and historical 
dramas. Similarly, Paul Erdős' unique sexuality, or rather asexuality, has been discussed in popular biographical works. John Nash's bisexuality, as documented in Sylvia Nasar's biography A Beautiful Mind, was consciously omitted from the movie version because the filmmakers feared that they would send the message that bisexuality and schizophrenia are related [9]. While such a message should clearly be avoided, what message did they send in its place? Indeed, what message do students get from reading biographies of mathematicians who are not "heteronormative?" When depictions involve female mathematicians, such as the relationship between Amita and Charlie, her advisor, on $N U M B 3 R S$, or the recent documentation regarding Einstein's mistresses, then other complicated questions arise. Students may notice, for example, that a biography of a female mathematician often mentions her marital status and if married, whether her husband has mathematical talent, whereas biographies of male mathematicians are less concerned with such matters. How should these issues be addressed in the classroom, especially if students make sexist or homophobic comments?

\section{Representations of Drug Use, Violence, and Illicit Activity}

In Proof (both the play and the screenplay), the character Hal comments about how mathematicians take drugs in order to remain competitive. He is most likely referring to Erdös' amphetamine use. What are the classroom consequences of discussing popular culture that describes drug use? Violence also inhabits mathematical popular culture. Historical biographies of Archimedes and especially Hypatia are steeped in violent imagery. On $N U M B 3 R S$, Charlie's skills are used to solve violent crimes, such as murder, kidnapping, stalking, and rape. How can we, as educators, be sensitive to these issues when we bring them into the classroom? Does violent imagery belong in mathematics?

\section{Conclusion}

Some may argue that our students are already desensitized to many of the problematic themes that arise in popular culture. But this does not absolve us of the responsibility to consider and address the implications of complex representations and stereotypes about mathematicians and their mathematics. Popular culture can be very effective in the classroom, and the related representations are memorable and can work well to entertain and generate interest in real mathematics. There are many more questions to be asked and answered, but regardless of what exactly constitutes "popular culture," studying its relationship with mathematics can be an exciting and rewarding endeavor.

\section{Acknowledgements}

Thanks to the Mathematical Association of America for their support of popular culture sessions at numerous conferences and to Brian Winkel for allowing us to serve as editors of this issue. 


\section{References}

1. ArtsConnectEd, "ArtsNet Minnesota: Identity Vocabulary," July 2006, Available: http://www.ArtsConnectEd.org/artsnetmn/identity/idvocab.html

2. Amy Dorsett, "Hip 2B"2," San Antonio Express-News, January 14, 2006, 1A.

3. Electronic Frontier "Unintended Consequences: Seven Years under the DMCA," April 2006, Available: http://www.eff.org/IP/DMCA/?f=unintended_consequences.html

4. LibraryLaw Blog, "Fair Use in (In)action," July 13, 2004, Available: http://blog.librarylaw.com/librarylaw/2004/07/copyfight_fair_.html

5. Mount Wachusett Community College Library, "Copyright Guidelines," July 14, 2004, Available: http://www.mwcc.mass.edu/library/copyright.html

6. PRIMUS, Special Section on Popular Culture in the Mathematics Classroom, XIV (1), 1-39, March 2004. Available: http://www.mathsci.appstate.edu/ sjg/papers/popculture/

7. Stanford University Libraries, "Stanford Copyright \& Fair Use - Summaries of Fair Use Cases," 2003, Available: http://fairuse.stanford.edu/Copyright_and_Fair_Use_Overview/chapter9/9-c.html

8. John Storey, Cultural Studies and the Study of Popular Culture: Theories and Methods, University of Georgia Press, Athens, 1996.

9. Rodger Streitmatter, "A Beautiful Mind," February 2002, Accessed: March 2006, Available: http://gaytoday.badpuppy.com/garchive/entertain/021102en.htm

10. Twentieth Century Fox Home Entertainment, Girls Just Want to Have Sums, original airdate April 30, 2006.

11. U.S. Copyright Office, "Digital Millennium Copyright Act," 1998, Available: http://www.copyright.gov/legislation/hr2281.pdf

12. U.S. Copyright Office, "Fair Use," July 2006, Available: http://www.copyright.gov/fls/fl102.html

13. U.S. Copyright Office, "Public Law 107-273," 2002, Available: http://www.copyright.gov/legislation/pl107-273.html\#13301

14. Wikipedia, "Popular culture - Wikipedia, the free encyclopedia," July 2006, Available: http://en.wikipedia.org/wiki/Popular_culture 